\title{
Las Juntas de Reformas Sociales y el Reformismo Social en la Restauración (1900 - 1924)
}

\author{
Felix Rubio López de La Llave
}

Solamente desde la perspectiva de los estudios de antecedentes del derecho laboral y de la nueva Administración de carácter social (Instituto de Reformas Sociales, Instituto Nacional de Previsión, Tribunales de Trabajo...), o desde el lado de las corrientes ideológicas que dan lugar al intervencionismo social-reformista del Estado, se han hecho aproximaciones referentes al objeto de este trabajo. Aparte, claro está, de los estudios que ha suscitado el movimiento obrero y, en general, el devenir político y los diversos proyectos revolucionarios. Incluso, más recientemente, se observa una mayor atención historiográfica con ocasión de la celebración del centenario de la Comisión de Reformas Sociales.

Ahora bien, si sabemos algo de las instituciones y del proceso ideológico y legislativo-parlamentario que desemboca en la primera legislación social desde 1900 , prácticamente no sabemos nada del proceso político que lleva a la aprobación de las leyes y, sobre todo, del proceso social y económico que implica y suscita la puesta en práctica de esas nuevas leyes de protección social o laboral: los factores y sectores sociales que las impulsan y las resisten. En definitiva, el estudio de la teoría y la práctica de la reforma social en las dos primeras décadas de nuestro siglo.

En efecto, no es hasta iniciado este siglo, salvando fracasados o, en todo caso, limitados ensayos previos, cuando se inicia lo que podríamos denominar como origen de nuestro derecho laboral que, progresivamente,

\footnotetext{
'Este trabajo es una sintesis de algunos de los capitulos de nuestra tesina de Licenciatura "Las Juntas de Reformas Sociales, (1900-1924)", leida en el Departamento de Historia Contemporánea de la UNED, en noviembre de 1986.
} 
irá constituyendo su corpus con las leyes sociales y protectoras nacidas, eso sí, casi siempre tarde y un poco a remolque de la realidad.

\section{DE LA COMISION AL INSTITUTO DE REFORMAS SOCIALES}

Decíamos que no es hasta entonces cuando conservadores y liberales unifican criterios y posturas intervencionistas en materia de legislación social. Preocupación suscitada y puesta de manifiesto en las dos últimas décadas del pasado siglo, y acelerada a partir de la publicación de la Encíclica de León XIII, conocida como Rerum Novarum, en $1891^{2}$. Tal preocupación queda probada con la creación de la "Comisión de Reformas Sociales", en diciembre de 1883.

El más importante trabajo realizado por ese organismo fue una información, oral y escrita, con fines estadísticos que sirviera, dada la absoluta desinformación oficial y privada de la situación social, para iniciar lo que se denominaba intervencionismo científico en las relaciones de trabajo. La citada información fue aportada desde diversos sectores interesados, patronales, obreros, profesionales, políticos e intelectuales que ante la citada Comisión intervinieron ${ }^{3}$.

Puede considerarse desde el punto de vista práctico que la Comisión representó un fracaso en líneas generales. Existe unanimidad a la hora de encontrar los motivos del poco éxito: escasez de medios, indiferencia en los más de los sectores políticos dominantes y, por último, la propia contestación obrera ${ }^{4}$. Sin embargo, no todo debe verse desde el lado negativo, por el contrario, se da como bueno el hecho mismo de su existencia; además, los trabajos estadísticos y de preparación legislativa no fueron del todo baldíos. Piénsese, por ejemplo, en las conocidas leyes de Dato acerca de "Accidentes del Trabajo" y del "Trabajo de las mujeres y de los niños en talleres y fábricas", de 1900; además de varios proyectos de ley que no llegaron a cristalizar en ese momento como leyes, así, el de huelgas

\footnotetext{
${ }^{2}$ F. Montero Garcia, "La polémica sobre el intervencionismo y la primera legislación obrera en España, 1890-1900". En Revista del Trabajo. Núms. 59 y 60 (1980) y 61 y 62 (1981).

${ }^{3}$ Los trabajos estadisticos e informativos llevados a cabo por ia Comisión pueden consultarse en la reedición llevada a cabo recientemente: Información oral y escrita. Comisión de Reformas Sociales. Reed. del Ministerio de Trabajo, 1985.

4 M.C. Palomeque, Derecho del trabajo e ideologia. Medio siglo de formación ideológica del Derecho español del trabajo, 1873-1983. Akal Univ., 1980, pág. 51.
} 
y coligaciones obreras, Consejo de conciliación y arbitraje, descanso dominical, etc.

Ya iniciado el nuevo siglo, y habiéndose hecho más generalizada la postura pro-intervencionista entre destacados políticos de los dos partidos turnantes, se inician los primeros pasos hacia la creación de un nuevo organismo que permitiera una nueva regulación en las relaciones de trabajo en España. Este nuevo organismo se crea por Real Decreto de 23-IV1903, y si la Comisión, que a partir de entonces deja de funcionar, refleja un cierto aire de provisionalidad, el nuevo organismo, denominado Instituto de Reformas Sociales, nace con una decidida vocación permanente, con mayor definición administrativa y jurídica y, sobre todo, con atribuciones claras y concretas. A lo largo de toda su historia, que se alarga hasta entrado el año 1924, el Instituto llegaria a tener bastante independencia, sobre todo hasta 1921, fecha en que pasa a depender del recién creado Ministerio de Trabajo. Se pretendía lograr con él un órgano neutral que sirviera de punto de encuentro y, a la par, de cauce, con el suficiente prestigio y asepsia política para que fuera creíble por los protagonistas sociales. El prestigio lo logró bastante, pero no pudo detener ni neutralizar el conflicto capital-trabajo a pesar de intentarlo desde un doble ámbito: a través de la legislación tutelar que presentaba al Gobierno para su promulgación, y el de la mediación y arbitraje que tantas veces intentó.

Sus creadores, regeneracionistas convencidos, estaban de acuerdo que, dado el reparto de la riqueza en España, el aumento asociativo de los trabajadores y la propia dinámica del proceso de producción, era latente el conflicto entre clases. Aumentado éste por la inveterada costumbre de la gran mayoría del empresariado español de permanecer libres sobre algo que les supusiera un obligado cumplimiento de leyes en materia socio-laboral. $Y$ ese enfrentamiento, pensaban, iba a ser duro (como lo demostraron los hechos). El I.R.S., precisamente, sería el órgano adecuado para frenar esa conflictividad que se avecinaba, actuando, al mismo tiempo, como organismo técnico capaz de crear la necesaria legislación laboral y como freno a las reivindicaciones obreras en materia social. Finalmente, el mismo organismo tendría las atribuciones precisas para que las leyes tutelares se cumplieran por medio de agentes inspectores. Servicio que sería uno de los primeros pasos dados por el Instituto.

Se intentó, en principio, crear un Instituto del Trabajo, debido a un proyecto de Canalejas en 1902, pero, tanto por las crisis ministeriales de principios de ese año y luego por el cambio de legislatura debido a la proclamación de la mayoría de edad de Alfonso XIII, el proyecto no llegó 
a convertirse en ley. Sin embargo, la decisión ya era firme; como hemos dicho el nuevo Instituto naceria un año después. $Y$, pese a la decidida postura de sus partidarios, tal y como lo manifiesta el propio CANALEJAS: "Entiendo que España no podrá desenvolverse ni vencer su crisis, más grave y más honda de lo que los gobernantes suponen, despreocupándose del malestar, del desasosiego social, cuyos rumores no llegan al salón de Conferencias ni al foyer de la Opera... Por eso creo que en la medida que a cada cual se lo permitan sus energías, debemos todos trabajar por la rápida implantación de reformas sociales... En esta obra patriótica... puede con eficacia y debe con legitimidad aportar el concurso de su intervención el Estado". ${ }^{5}$ Tanto el fracasado intento de Canalejas, como la propia creación del I.R.S. (siendo Presidente del Consejo de Ministros el conservador Silvela), no dejó de causar oposición. Prueba el dato de que la idea de la intromisión gubernamental en asuntos laborales no era generalizada, la opinión de dos atentos y expertos observadores de la cuestión social, BUYLLA y POSADA, que manifiestan: "Cuando pasen los años y el historiador 0 el sociólogo de los tiempos futuros, quieran penetrar en la íntima substancia de este período y explicarse las causas de la viva resistencia que encontró la idea del Instituto del Trabajo, se extrañarán al leer ciertos discursos, al hojear las páginas del Diario de Sesiones. Ellas están revelando la existencia de una "edad de piedra" en cuanto a las doctrinas sociales. Y más adelante se señala con dureza no exenta de cruel sarcasmo: "Si no se llegó a pedir - en las Cortes - que se oprimiera más al proletariado, no faltaron oradores que, erigiéndose en abogados de la propiedad individual, que allí ningún hombre de gobierno atacaba, sostuvieran la necesidad de mantener el statu quo, porque harto hacían el Estado y la sociedad en pro de los trabajadores, dándoles instrucción gratuita, pan y cama en el hospital, un voto que vender, para que éstos tuvieran todavía el "valor" de quejarse" 6 .

Pese a todo ello, el recién creado Instituto logró arrancar con fuerza, ideado teniendo en cuenta las experiencias de organismos análogos de otros países ${ }^{7}$.

\footnotetext{
${ }^{5}$ A. Buylla, A. Posada, L. Morote, El instituto del Trabajo. Datos para la historia de la reforma social en España. Centro de Publicaciones, Ministerio de Trabajo y Seguridad Social, 1986. Págs. IX y XI, del prólogo escrito por don José Canalejas para esta obra realizada bajo su inspiración y patrocinio.

${ }^{6} \mathrm{lbid}$. Págs. 96 y 97.

7 En efecto, fueron estudiados y algunos de ellos visitados diferentes organismos internacionales en los que se basó tanto el proyecto canalejista como el posterior I.R.S. En Francia funcionaba el "Office du Travail", desde 1891; y en Bélgica, con el mismo nombre, desde 1894. Los "Bureau of Labor", (1884), convertido luego en "Departament of Labor" desde 1888, norteamericanos. Los "Labor Departament" (1893), y los "Board of Trade" británicos. La "Arbeiter-statistik" (1892) alemana. La "Ufficio de Lavoro" (1901) italiana; y de otros países,
} 
En los primeros artículos del recién creado Instituto quedan especificados sus cometidos: "Encargado de preparar la legislación del trabajo en su más amplio sentido, cuidar de su ejecución, organizando con ello los necesarios servicios de Inspección y Estadística, y favorecer la acción social y gubernativa en beneficio de la mejora o bienestar de las clases obreras ${ }^{8}$.

Como vemos en este primer párrafo de su constitución, queda claro el propósito intervencionista y reformador. Sus funciones aparecen nítidamente en el articulado de su Reglamento: "Preparar la legislación del trabajo en su más amplio sentido" (Art. $3^{\circ}$ ). "Organizar los servicios de inspección y estadística...", y ello referido a los diferentes ámbitos central, provincial y local (Art. $4^{\circ}$ ). La función mediadora queda explicitada en el artículo 5: "... para prevenir los conflictos o resolverlos". $Y$, finalmente, queda constituido como cuerpo consultivo permanente de la Administración según lo regula el artículo $6^{\circ} 9$.

Inicia el lístituto su andadura ${ }^{10}$ bajo la presidencia del republicano, regeneracionista convencido, Gumersindo de Azcárate, y en su composición figuran hombres de diversa procedencia y filiación política, pero todos ellos animados, con mayor o menor decisión o voluntad, en las tareas de la reforma social. Por el lado obrero, y desde 1904, fecha de las primeras elecciones para cubrir sus puestos de Vocales, hasta su disolución en 1924, permanecieron en su seno sindicalistas de la UGT, salvo breves paréntesis coyunturales en que permanecieron al margen: Largo Caballero y Francisco Mora fueron sus más significativos portavoces.

Además de constituir el I.R.S. el organismo propulsor de toda la "catarata" legislativa en materia social, de la realización de los trabajos estadísticos de tipo socioeconómico, y de informes, estudios y proyectos de naturaleza sociolaboral, todo ello a lo largo de su existencia, se encargó de la inspección y mediación en las relaciones de trabajo, y es en este apartado crucial donde ocuparon un lugar importante las Juntas de Reformas Sociales. Creadas con anterioridad al Instituto, es este organismo el que las potencia en atribuciones y facultades, y del que dependen.

Austria, Suiza, Hungria..., de todo y cada uno de estos organismos oficiales de carácter social, nuestros reformadores sociales tenian completo conocimiento, y de ellos se copiaron modelos organizativos, composición, objetivos y experiencias.

${ }^{8}$ Boletin del Instituto de Reformas Sociales, (BIRS). N. ${ }^{\circ}$, julio, 1904.

${ }^{9}$ BIRS. N. ${ }^{\circ}$ 2, agosto, 1904.

${ }^{10}$ I.R.S. Memoria sobre el Instituto de Reformas Sociales, 1904-1915. Sobr. de la S. ${ }^{a}$ de M. Minuesa de los Ríos, pág.: 176. 


\section{LAS JUNTAS DE REFORMAS SOCIALES. CREACION Y FUNCIONAMIENTO INTERNO}

Estos organismos nacen con las primeras disposiciones legales de contenido social de 1900: son enunciadas en la de Accidentes de Trabajo (30-1-1900), y creadas, de hecho, en la que se regula el trabajo de mujeres y niños (13-III-1900). Sin embargo, en los cuatro primeros años de andadura, estos organismos carecieron de uniformidad en cuanto a su funcionamiento y el nivel de participación social en ellas fue escaso o, en la mayoría de casos, inexistente. No es hasta la promulgación de la Real orden de 3-VIII-1904, en la que quedaron formadas o aclaradas las normas de constitución y funcionamiento de las Juntas, cuando comienzan a tener influencia y participación social relevante, y ello es porque solamente desde ese año comienza la participación importante de los representantes sociales en las Juntas, por el lado obrero especialmente, y a consecuencia de que no es hasta entonces cuando se celebraron las primeras elecciones para optar a los puestos en las Juntas, (lo mismo que a las Vocalías del I.R.S.).

Las Juntas nacen, en principio, con una dedicación específica, y es la de "inspeccionar todo centro de trabajo, procurar el establecimiento de Jurados mixtos de patronos y obreros, entender de las reclamaciones que unos y otros sometan a su deliberación y velar por el cumplimiento de la Ley, singularmente donde se reúnen obreros de ambos sexos, para que se observe una disciplina que evite todo quebranto de la moral o de las buenas costumbres" ${ }^{\prime 0}$. Son, además, órganos consultivos de alcaldes y gobernadores -en éste último caso se refiere a las Juntas provinciales de naturaleza representacional de obreros y patronos elegidos cada cuatro años, "que vienen a ser escala de la suprema representación que en el Instituto de Reformas Sociales tienen patronos y obreros" 11. Las Juntas dependieron del Instituto que les da nombre, y estaban ligadas directamente a la Inspección Central de la Sección $2^{\mathrm{a}}$ del Instituto.

Como vemos, estos organismos tienen una misión tutelar relacionada estrechamente con la ley de mujeres y niños; además de convertirse en comisiones mixtas permananentes bajo la presidencia de Alcaldes y Gobernadores civiles y, en mayor instancia, del propio Instituto. La escasez de inspectores y la posición de las Juntas en la vida local de las ciudades donde fueron constituidas, hacen que, conforme avanza la legislación la-

${ }^{10}$ I.R.S. Memoria sobre el Instituto de Reformas Sociales, 1904 1915. Sobr. de la S. ${ }^{\text {a de M. }}$ Minuesa de los Ríos, pág.: 176.

11 Ibid. Pág. 177. 
boral, se las vayan añadiendo atribuciones y facultades de manera ininterrumpida.

Mencionamos anteriormente que por la R.O. de 3-VIII-1904 quedaron constituidas las normas con que estos organismos regularon su actuación a lo largo de su existencia. Claro que, con el paso del tiempo, se continuaron promulgando disposiciones y ampliaciones de esa Real orden surgidas ante la experiencia que el tiempo y las nuevas circunstancias iban imponiendo. Aunque muchas de esas disposiciones eran simples repeticiones parciales de aquella Real orden originaria.

Las Juntas se constituirán en todos los municipios donde radicara alguna industria o cualquier tipo de explotación que implicara la existencia de patronos y obreros, y donde lo pidieran unos u otros. De esta forma, en la práctica, podían constituirse en cualquier lugar de España si tenemos en cuenta la enorme dispersión artesanal y comercial. Fácilmente, el legislador hubiera podido coartar tal libertad, exigiendo, por ejemplo, un mínimo de obreros ocupados en las ciudades o pueblos donde fuera a crearse una Junta, pero con ello se hubiera falseado su directriz esencial: la vigilancia y defensa de las llamadas "medias fuerzas" productivas, ya que tal sector productivo dependía en gran medida de talleres y explotaciones familiares enormemente diseminadas.

Las Juntas se componían, en primer lugar por el alcalde (en las provinciales por el gobernador civil), como representante de la Autoridad civil, quien actuará como Presidente de la Junta; por el párroco del lugar, si hay más de uno por el de mayor antigüedad; y por el médico titular, o también si existiese más de uno por el decano de ellos en la ciudad. Más adelante sería la Real Academia de Medicina, por méritos y servicios, quien haría la propuesta y el Instituto ratificaría el nombramiento. Ellos completan los integrantes natos de las Juntas, y nunca bien vistos por las Asociaciones obreras. Se solicitó por éstas que, en todo caso, tuvieran voz en la Junta pero no voto, cuestión ésta que rechazó el I.R.S. en $1908{ }^{12}$.

Además de ellos, componían las Juntas los vocales representativos de patronos y obreros, o vocales electivos, que era como se les denominaba. No podían ser más de seis por cada una de ambas representaciones, lo normal es que fueran cuatro, y siempre había unos suplentes igualmente elegidos. El número de estos vocales debería ser igual de una representación y otra. Su actuación duraba cuatro años y podian ser reelegidos ininterrumpidamente.

\footnotetext{
${ }^{12}$ BIRS. N. ${ }^{\circ}$ 51, septiembre, 1908.
} 
La ley obligaba por la regla novena de la misma, que las Juntas renovasen la parte electiva cada dos años, de modo que la mitad de cada representación fuera ocupada por los vocales suplentes según fueran cumpliendo los cuatro años de antigüedad en el cargo los titulares, y como quiera que, una vez constituida una Junta, transcurridos dos años ninguno de sus miembros alcanzaba la antigüedad referida, la renovación se haría mediante sorteo. De estas manera, en las sucesivas renovaciones irian saliendo aquellos que alcanzasen los cuatro años de ejercicio. Tal circunstancia provocó numerosas aclaraciones del I.R.S. Su motivación es doble; por un lado se logra movilidad entre los vocales; por otro, se evita que cualquier Junta al iniciar su actuación se encuentre que todos sus vocales sean nuevos y sin experiencia.

La elegibilidad se lograba mediante la inscripción en cualquier sociedad obrera o patronal, independientes una de la otra (no fueron aceptados muchos Círculos Recreativos de obreros y Sociedades mixtas), que radicase en el ámbito territorial de la Junta y estuviera legalmente constituida. En aquellos lugares donde no se hubiese constituido sociedad obrera o patronal, se convocaba a los patronos y obreros de las distintas clases y oficios, separadamente, y considerando a cada grüpo como gremio o sociedad votaban a los miembros que habían de constituir los Vocales representativos de la Junta de Reformas Sociales.

$\mathrm{Ni}$ que decir tiene que muchas de estas elecciones fueron manipuladas $\circ$ fraudulentas; cuando tal cosa sucedía, siempre que hubiese una sociedad o particulares perjudicados, interponían recurso al gobernador civil de la provincia o, en segunda instancia, al propio Instituto de Reformas Sociales, quien a lo largo de su historia tuvo que anular numerosas elecciones celebradas, incluso revocando providencias de los gobernadores. Sin duda quienes más utilizaron el recurso pidiendo la anulación de elecciones fueron las sociedades obreras. Los motivos más normales por los que se originaba la protesta eran los de no haber convocado a las partes con antelación, la exclusión de alguna sociedad obrera o patronal por parte del alcalde o, por el contrario, la inclusión de una sociedad que a juicio de alguna parte afectada no debiera concurrir a la elección; por ejemplo, una sociedad obrera con injerencia patronal, o la denuncia de la Federación de Sociedades obreras de Zaragoza contra la elección de vocales obreros por haber participado en ella una Sociedad socialista de carácter "político", y figurar burgueses (patronos) en la candidatura ${ }^{13}$.

${ }^{13}$ BIRS. Año 1907. 
Uno de los aspectos que contemplaba la ley que comentamos es el establecimiento de dietas a los vocales obreros. Con ello se intentaba estimular la participación obrera en las Juntas. Las dietas eran de tres pts. por cada día que obligase al vocal obrero por el ejercicio de su cargo a perder su jornal. Esta cantidad podía ser elevada a cinco pts. en aquellos lugares cuyo jornal medio excediese de la primera cantidad expresada. Si bien el I.R.S. autorizó siempre las solicitudes de aumento que se pidieron, otra cosa fue la desgana, incluso la firme negativa, con que algunos alcaldes acogieron la obligación del abono de estas dietas.

Las elecciones para la constitución de Junta local tuvieron lugar en 1904 las primeras, ${ }^{14}$ en 1908 y en 1912, además de las que por carácter extraordinario o por nueva creación se constituyeron. Desde la última fecha indicada la creación de Juntas sufrió un parón a consecuencia de las disputas y falta de acuerdo en la forma de la elaboración del Censo electoral social. El más grave desacuerdo se formó en torno a qué tipo de sociedad obrera debía considerarse como tal, es decir, su definición en función a sus estatutos. Salió triunfante la tesis obrerista, por lo que muchas sociedades mixtas, Círculos católicos y sociedades recreativas tuvieron que cambiar su carácter, objetivos y estatutos si querían concurrir a las elecciones de naturaleza social: Tribunales de trabajo, Instituto de Reformas Sociales y Juntas.

Este censo no quedó ultimado hasta 1922, siendo las elecciones para Juntas de Reformas Sociales en el siguiente año, las primeras desde 1912, salvo una convocatoria extrordinaria en 1919; debido a la mala situación y escasa participación de los vocales electivos en las Juntas como consecuencia de la prohibición de celebrar elecciones desde 1912.

\section{PRINCIPALES ATRIBUCIONES DE LAS JUNTAS LOCALES DE REFORMAS SOCIALES}

Prácticamente en todas las leyes y sus reglamentos de índole laboral que fueron promulgados en estos años hay una referencia hacia las Jun-

\footnotetext{
${ }^{14}$ Las primeras controladas por el I.R.S. y con normas definidas de composición y funcionamiento emanadas de la ley de 3-VIII-1904, ya que con anterioridad se celebraron elecciones para constituir Juntas de Reformas Sociales en 1900, por R.O. de 9 de junio de ese mismo año, convocándose para los meses de julio y agosto. En esta ocasión el número de Juntas constituidas fue muy bajo; además su forma organizativa y funcional queda establecida muy someramente y de manera provisional.
} 
tas, bien sea en la ley o disposición principal o en las posteriores que las amplían o complementan.

Es la Ley de 13 de marzo de 1900, en la que se establecen las condiciones de trabajo para mujeres y niños, la que da origen de manera efectiva y real a las Juntas de Refomas Sociales, y a través de su artículo $7^{\circ}$ : ... Serán atribuciones de estas Juntas: inspeccionar todo centro de trabajo; cuidar de que tengan condiciones de salubridad e higiene; formar las estadísticas del trabajo; procurar el establecimiento de Jurados mixtos de patronos y obreros; entender en las reclamaciones que unos y otros sometieren a su deliberación; y velar por el cumplimiento de esta ley... ${ }^{15}$. Los artículos del $12^{\circ}$ al $15^{\circ}$ de la ley dan más facultades a las Juntas. Igualmente en el Reglamento de la misma se completan las atribuciones referidas a la inspección y clasificación de industrias e imposición de sanciones; aunque en este último caso la facultad corresponde al Presidente de la Junta, esto es, al alcalde, quien posee el poder resolutorio y ejecutivo. La Junta, en lo referido a imposición de sanciones sólo tiene atribución meramente consultiva.

El R.D. de 20-VI-1902, en el que se regulan las condiciones de trabajo en las concesiones de obras públicas otorgadas por el Estado y organismos provinciales y locales públicos, por su artículo $2^{\circ}$ establece que sean las Juntas las que se encarguen de las diferencias suscitadas entre los obreros y los concesionarios de las obras. Otro R.D. de 26-VI-1902 que fija el límite de la jornada de trabajo en once horas para las personas comprendidas en la ley de mujeres y niños, encarga a las Juntas la vigilancia e inspección sobre el cumplimiento del mencionado límite horario.

Son numerosas, por otra parte, las disposiciones que establecen las normas y formas de realizar la inspección de trabajo en todo centro industrial, sobre todo en los lugares donde no residieran los inspectores del trabajo o allí donde se conociera una infracción legal.

Gran importancia tuvieron las diferentes leyes relativas al descanso que concedieron amplias facultades a las Juntas. La promulgada el 3-III-1904, y su Reglamento, estableciendo el descanso dominical, regula que sean las Juntas las encargadas de consignar las excepciones en el cumplimiento de dicha ley. Graves dificultades hubo con las excepciones en la apertura de tabernas de las poblaciones de menos de 10.000 almas y donde existieran o se concedieran ferias y mercados de carácter tradicional. Ambos aspectos dieron a las Juntas una importancia y protagonismo en la vida local realmente importantes.

${ }^{15}$ Gaceta, 14 de marzo de 1900. 
Una disposición legal importante que tuvo gran repercusión para las Juntas, fue la Ley electoral de 8 de agosto de 1907. Por esta Ley (art. 11, párrafo 8), las Juntas municipales del Censo que en cada Ayuntamiento habían de constituirse, debían de ser presididas por uno de los Vocales de la Junta de Reformas Sociales. Habida cuenta del interés electoralista, se produjo una verdadera vorágine en constituir Juntas de Reformas Sociales en todos los rincones del país. Tal disposición trajo numerosos problemas que desvirtuaron la labor y cometido de las Juntas. Muchas se crearon, sobre todo en el medio rural donde el interés partidista y caciquil era más notorio, con el exclusivo motivo de copar la presidencia de la Junta municipal del censo.

Numerosas atribuciones informativas y estadísticas, además de inspectoras, se dieron a las Juntas a través de la diferente legislación en materia reguladora de la jornada laboral. Como en la que se limita la jornada máxima en 60 horas a la semana 03.000 al año para la industria textil, de 24-VIII-1913; la que regula la jornada en establecimientos industriales, de 4-VII-1918. Por ellas, o por sus Reglamentos de aplicación, las Juntas podían fijar los horarios en cada establecimiento, establecer las horas de descanso para comer los empleados, oír y conformar los acuerdos y pactos entre las partes, y la facultad más importante: la designación de excepcionalidad en aquellos establecimientos que lo solicitasen y la Junta así lo acordara.

De esta manera las Juntas vuelven a convertirse en protagonistas de la vida comercial en los lugares donde estuviesen constituidas. Ellas podían determinar, por ejemplo, si las tabernas y bares eran o no casas de comidas, porque de declararlas como tales podían ser exceptuadas en el cumplimiento de la ley. Es cierto que se limitó por el Reglamento de la última ley citada el que las Juntas pudiesen condonar las sanciones, ante el temor, más que fundado, de que las Juntas fueran dominadas por la burguesía local y comerciante e hicieran caso omiso de las sanciones impuestas por los inspectores de trabajo o por los mismos vocales obreros de las Juntas. Tal limitación aprobada por el Pleno del Instituto fue propuesta por el vocal socialista Francisco Mora ${ }^{16}$.

Tales leyes provocaron gran desconcierto y confusión, como lo prueba el gran número de instancias solicitando aclaración procedentes de Asociaciones obreras, patronales, Gremios mercantiles, incluso de las propias Juntas. El Instituto, a través de circulares y Reales órdenes, aclara en

\footnotetext{
${ }^{16}$ BIRS. N. ${ }^{\circ} 175$, enero, 1919.
} 
lo que puede la situación promovida por tales leyes reguladoras de la jornada laboral que, en definitiva, no satisficieron a nadie.

EI R.D. de 15-III-1919 establece la jornada máxima de ocho horas en los oficios del ramo de la construcción; otro R.D. que limita el trabajo nocturno en panaderías y similares; y por fin el que establece la jornada máxima de ocho horas o 48 a la semana en toda clase de trabajo (3-IV1919), todos ellos conceden facultades a las Juntas sobre qué tipos de pactos podían establecerse entre patronos y obreros, la realización de turnos entre los empleados y, sobre todo, quiénes podían redimirse por excepcionalidad en el cumplimiento legal. Además, naturalmente, de las ya clásicas atribuciones de inspección como auxiliares de este servicio de los inspectores de trabajo.

Tales atribuciones fueron ratificadas y ampliadas mediante el R.D. de 21-VIII-1919, por el cual se concedía a las Juntas la potestad, en primera instancia, de otorgar la excepcionalidad en el cumplimiento de la ley de las ocho horas. Así, todos los comercios, bares, tabernas, Bancos y oficinas, todo tipo de transportes y gran número de fábricas y talleres, debían de solicitar a las Juntas si esos centros de trabajo podían quedar exceptuados, para que se pronunciaran antes del primero de octubre de ese año. En los casos de desacuerdo resolvería el Instituto antes del uno de enero de 1920, para que de esta manera ya estuviese cumpliéndose exceptuada, según el caso, la nueva normativa. Incluso si en una ciudad no hubiera Junta constituida entendería en las solicitudes de excepción o reclamaciones la Junta local más próxima.

Se nota la prisa del Gobierno en establecer la jornada de ocho horas, adelantándose así a muchos países industrializados, para quitar tan importante arma reivindicativa a las ya potentes fuerzas sindicales, y para acallar en lo posible la protesta obrera en momentos fuertemente críticos para el régimen.

Sucesivamente siguen dictándose normas relativas a la jornada, y con ello se van aumentando las atribuciones a las Juntas de Reformas Sociales. Como la vigilancia de los reincidentes a la ley, la autorización para aplicar y vigilar el cumplimiento de ias horas extraordinarias (50 en un mes o 100 en un año); y una ingente normativa particular y concreta referida a cada Junta y a los diversos acuerdos que adoptaron estos organismos en esta materia.

Además de todas estas atribuciones habría que añadir las que se refieren a funciones arbitrales y de conciliación en huelgas y conflictos, ins- 
pección de la ley reformada de accidentes de trabajo, y otras de índole estadística e informativa.

Resumiendo todo lo anterior, salta a la vista que las principales atribuciones concedidas fueron las referidas a las leyes protectoras de mujeres y niños y las dedicadas a regular el descanso y los horarios de jornada. $Y$ dentro de estas facultades sobresalen las que se refieren a la inspección en el cumplimiento de tales leyes. Sin embargo, todas estas facultades, como veremos, no determinan que las Juntas posean atribuciones realmente efectivas en hacer cumplir la ley, pues siempre es su presidente, el alcalde, quien tiene las mayores prerrogativas al ser él quien puede poner sanciones. Elemento ciertamente no baladí si tenemos en cuenta su eficacia coercitiva. Se impone, por lo tanto, adoptar el criterio de separar, o al menos distinguir siempre, lo que es una Junta de Reformas Sociales, con gran cantidad de atribuciones legales a su cargo, que esté bien constituida y sea representativa de las dos clases en litigio social, y quienes ostentaron la máxima facultad dentro de las Juntas, es decir, los alcaldes que, casi siempre, estuvieron vinculados a la clase que pertenecian. Esta distinción la realizan los mismos inspectores de trabajo, a pesar de que estos funcionarios mantuvieron siempre una clara oposición y enfrentamiento con las Juntas, debido, sobre todo, a la duplicidad de competencias. Así, el inspector de la región andaluza, en la Memoria de 1914, aunque podríamos entresacar opiniones similiares, realiza la distinción que mencionamos: "...más que a los individuos de ellas - las Juntas - , es imputable a los alcaldes, como presidentes de las mismas, pues muchas veces los componentes de las Juntas piden la debida sanción para los infractores de la legislación obrera y la Autoridad local no ha hecho nada por hacer efectivas las multas acordadas" 17.

En definitiva, fueron las Juntas más organismos mixtos consultivos de los alcaldes que instrumentos efectivos de que la ley laboral se cumpliese en cada localidad donde aquel organismo estaba constituido.

\section{IMPLANTACION Y DIVERSIDAD DE LAS JUNTAS DE REFORMAS SOCIALES}

Quienes solicitaban la constitución de las Juntas eran, en primer lugar, los trabajadores allí donde tenían sociedad constituida. En menor medida

\footnotetext{
${ }^{17}$ IRS. Memoria General de la Inspección de Trabajo de 1914. S. ${ }^{a}$ de M. Minuesa de los
} Rios, 1916. Pág. 177. 
también los Gremios patronales solicitaban la constitución de Juntas; y los alcaldes, bien por interés político propio o por el hecho de cumplir la ley, en ocasiones tomaban la iniciativa en crearlas; y, finalmente, el I.R.S. instaba a que fueran constituidas en los lugares donde había industrias y aún no se hubiese creado la Junta.

Sin embargo, en los tres primeros años desde la promulgación de la Ley de Mujeres y niños y su Reglamento, en 1900, no fueron muchas las Juntas creadas. Solamente en las capitales de provincia, y no en todas, y en otras ciudades importantes. El rechazo frontal del sindicalismo anarquista, que, por otra parte, duró todo el tiempo de vida de las Juntas; el radicalismo anticolaboracionista que por entonces, no ya por mucho tiempo, sostenía el sindicalismo socialista, y el desinterés generalizado de las Autoridades, fueron la causa del escaso interés en la creación de los nuevos organismos de seguimiento de las leyes laborales.

Con la llegada de los vocales socialistas al Instituto en su primera elección de 1904 y de los representantes de las entidades patronales de mayor implantación e importancia en toda España, el número de Juntas debió triplicarse, y progresivamente se fue ampliando su número hasta alcanzar las 500 Juntas a mediados de 1907.

De esta manera se llega a una fecha clave en la evolución cuantitativa de las Juntas; nos referimos a la promulgación de la mencionada ley Electoral de agosto de 1907. En efecto, la facultad de que sean las Juntas quienes se encarguen de elegir de entre sus vocales al que habría de presidir la Junta municipal del Censo, hace que el número de aquéllas aumente de forma espectacular. Con ello, ciertamente, se desvirtúa el objetivo inicial de las Juntas y también se falsea su importancia numérica, ya que todas ellas - las que se crearon por impulso de la ley Electoraltenían como único motivo la elección de Presidente de la Junta municipal del Censo.

A partir de 1907, y por el motivo aludido, el número de Juntas se va incrementando. Así, en 1908 se constituyen más de 2.000 Juntas. En 1909 el Instituto confirma que su número pasa de las 4.000 , y muy poco después se alcanzaban las 5.842 Juntas, concretamente al 31 de diciembre de 1909; número bastante respetable si tenemos en cuenta la cantidad de municipios españoles que por su importancia industrial hubiera hecho necesario la creación de Juntas de Reformas Sociales.

A partir de 1910 comienza la inflexión de su número, situándose en las 1.613 Juntas en diciembre de 1915. Esta importante disminución se 
explica por dos causas. Primero, por la prohibición de crear o renovar Juntas desde 1912 hasta la finalización del Censo electoral social. Y en segundo lugar, porque, una vez elegido el presidente de la Junta municipal del Censo, estos cargos no fueron renovados como lo indicaba la propia ley Electoral. Con ello, las Juntas creadas por este exclusivo fin, ni realizaban alguna actividad ni renovaron su constitución que les permitiera dar alguna señal de vida.

La ley excepcional de 1919 ordena la renovación de Juntas sin celebrar elecciones, es decir, completándolas de acuerdo con el resultado electoral de cada Junta obtenida en las últimas elecciones, en 1910 o 1912. De todas formas la disminución va acentuándose hasta llegar a las 900 Juntas en 1921, en diciembre. $Y$ de esas 900 solamente mantienen relación regular con el Instituto unas 63 Juntas. Desde entonces carecemos de datos cuantitativos fiables de la evolución numérica de las Juntas. Sabemos, sin embargo, que el número aumenta a raíz de las elecciones de 1923. Pese a ello, no debieron de pasar de las mil Juntas a finales del siguiente año. Incluso debieron reducirse por la nueva situación política en España, además de por el propio fracaso de muchas Juntas y por la competencia de otros organismos paralelos, como los Comités paritarios, según lo denuncia un inspector de trabajo ${ }^{18}$.

Las Juntas, ya convertidas desde junio de 1924 en Delegaciones locales del Consejo de Trabajo, prosiguieron su evolución cada vez de manera más lánguida e, imaginamos, que su número fuera disminuyendo. El poco interés por estos organismos que expresó la política social primoriverista, queda reflejado por la tardanza de un nuevo Reglamento que regulara a las nuevas Delegaciones: tardó seis años en publicarse, promulgándose en 1930 (19 de junio). Por este Reglamento se suprimen todas las Delegaciones constituidas en lugares que no sean cabezas de partido judicial, aparte de las capitales de provincia, (aunque por su Disposición Transitoria $3 .^{a}$ podían constituirse en lugares de gran movimiento industrial siempre que lo aprobase el Consejo de Trabajo y fuera solicitado por los interesados sociales dentro de los tres primeros meses desde la publicación del Reglamento).

Si nos referimos ahora a la distribución geográfica, podemos hacer también algún tipo de reflexión. Así, en 1909, cuando se alcanzan las 5.842 Juntas, el mayor número de ellas corresponden a provincias casteIlanas como Salamanca, con 374 Juntas constituidas, Guadalajara (360),

${ }^{18}$ Ministerio de Trabajo y Previsión: Memoria de la Inspección de Trabajo correspondiente a 1929. Sobr. de la S. ${ }^{a}$ de M. Minuesa de los Ríos, 1930, pág. 182. 
Cuenca (280), Burgos (250), Valladolid (230), y también Cáceres (222), y luego Barcelona. Esta última provincia, con respecto a las anteriores, altera el tipo regional, además de la estructura económica, población y ocupación de la misma.

Otro grupo de provincias, entre 151 y 200 Juntas, mantienen lageneralidad del carácter del grupo anterior, se integran en este grupo: Avila, Badajoz, Huesca, Lérida, Segovia y Sevilla.

En los dos siguientes grupos que podriamos formar, entre 101 y 150 y entre 51 a 100 Juntas, se incluyen la mayoría de las provincias, correspondiendo a ambos grupos la mayor diversidad entre ellas. Las hay maritimas, del interior, con mayor o menor población o peso industrial, etc.

El último grupo, provincias con menos de 50 Juntas constituidas, corresponde a zonas litorales, excepto Soria y Alava, la última con sólo 50 organismos creados.

En diciembre de 1915 se produce una drástica disminución en elnúmero de Juntas. Desaparecen más de 4.200 y también se altera su distribución relativa.

Ninguna pasa ahora de las 300 Juntas, y solamente Guadalajara supera las 200. Tampoco hay ninguna provincia dentro del grupo entre las 151 y 200. Solamente hay una, Avila, que cuenta con más de 100. La gran mayoría de las provincias se integran entre las que tienen menos de 50 Juntas, y aún la mayor parte tienen menos de 25. En este último subgrupo destaca Salamanca, que seis años antes pasaba de las 300 y ahora sólo tiene 23 Juntas constituidas; o Valladolid, con 18. Alava mantiene el menor número, ahora sólo con dos.

En marzo de 1920, a partir de las cifras que poseemos y de su distribución, se confirma el proceso de disminución anterior. Figuran registradas en el Instituto 1.341 Juntas. La provincia que más tiene es Burgos, con 141; todas las demás se encuentran por debajo de las 100 , y pocas con más de 50, tan sólo Navarra con 84 y Salamanca con 76 . El resto tiene menos de 50 Juntas. Aparte de la de Ceuta. Alava con cinco y Huesca con tres son las que tienen menos.

Sin embargo, pese a la clara disminución del número de Juntas, se produce una mayor racionalización en su distribución. En efecto, hay ahora más provincias dentro del grupo entre 25 y 50 que en 1915, constituyendo este grupo la mayoría frente al de ese año que lo era el de menos 
de 25. Las que tenían más Juntas constituidas disminuyen siguiendo el descenso general, pero las que tenían muy pocas suben algo.

De todas formas, estos datos solamente tienen un valor indicativo y muy escaso si queremos realizar un análisis comparativo. Decimos esto, porque al ser las Juntas organismos de carácter municipal, habría que tener en cuenta el número de Ayuntamientos de cada provincia. No es lo mismo Cádiz que Guadalajara, aquella provincia no podía tener más de 42 Juntas de Reformas Sociales, al ser ese el número de sus municipios, mientras que la otra podía llegar a las 398 Juntas.

Ofrecemos a continuación un cuadro con un grupo de provincias que nos han parecido representativas. En él mostramos el número de municipios de que constan, el de Juntas en los tres momentos que hemos visto y sus respectivos porcentajes.

\begin{tabular}{lccccccc}
\hline & $\begin{array}{r}\text { N. }{ }^{\circ} \text { de } \\
\text { Ayunta- } \\
\text { mientos }\end{array}$ & $\begin{array}{c}\text { N.R.S. } \\
1909\end{array}$ & $\%$ & $\begin{array}{c}\text { N.R.S. } \\
\text { J.Rovincias }\end{array}$ & & $\begin{array}{r}\text { N. }{ }^{\circ} \text { de } \\
\text { J.R.S. } \\
1915\end{array}$ & $\%$ \\
\hline Cádiz & 42 & 42 & 100 & 18 & 42,3 & 9 & 21,4 \\
Huelva & 78 & 77 & 98,7 & 15 & 19,2 & 47 & 60,2 \\
Guipúzcua & 87 & 48 & 55,2 & 21 & 24,1 & 21 & 24,1 \\
La Coruña & 108 & 64 & 59,3 & 18 & 16,7 & 24 & 22,2 \\
Badajoz & 162 & 162 & 100 & 35 & 21,6 & 45 & 22,3 \\
Granada & 198 & 131 & 66,2 & 45 & 22,7 & 25 & 12,6 \\
Navarra & 275 & 130 & 47,3 & 17 & 6,2 & 84 & 30,6 \\
Barcelona & 330 & 216 & 65,5 & 79 & 23,9 & 32 & 9,7 \\
Soria & 345 & 38 & 11 & 14 & 4,1 & 12 & 3,5 \\
Guadalajara & 398 & 360 & 90,5 & 269 & 67,6 & 42 & 10,6 \\
\hline
\end{tabular}

Fuente: Elaboración personal a partir de los BIRS. de 1908 a 1921. 
Vemos en el cuadro que hay provincias con alto número de municipios que alcanzan también altos porcentajes de Juntas, incluso del ciento por cien. Por el contrario, llama la atención que haya provincias con bajos índices, como Soria.

En 1915, al producirse el descenso de Juntas constituidas, lógicamente disminuyen los porcentajes con respecto a sus Ayuntamientos. Esto ocurre en todas las provincias, en algunas de manera espectacular, como en Huelva, que pasa del 99 por 100 al 19.

En 1920, pese a que la disminución sigue, el porcentaje se equilibra, salvo excepciones; ello se debe a que sube el número de Juntas en bastantes provincias, hay una mayor homogeneidad, sin tantas diferencias como en 1915.

Para hablar sobre la diversidad de las Juntas lo ideal sería hacer un estudio y análisis desde la propia documentación interna de cada una. En muchos casos tal estudio será ya imposible por la pérdida de la documentación en los archivos municipales, pero en otros todavía se podrían realizar trabajos particulares y pormenorizados. En el presente caso, y por las fuentes utilizadas, como son las del Instituto de Reformas Sociales, se puede en todo caso realizar una serie de aproximaciones sobre el particular.

En primer lugar, si hacemos una distinción basada en la actividad de las Juntas, podríamos distinguir por un lado las activas, que son minoría sobre el total de las existentes. En ellas se da la preceptiva representación equilibrada de obreros y patronos. Corresponden a centros poblacionales con vida industrial. En este caso no debe incluirse muchas de las capitales de provincia, como Soria, Teruel, Vitoria, Huesca, Logroño, Palencia... en que su Junta local o no estaba constituida la mayoría del tiempo o no funcionaba nunca.

Este grupo de Juntas activas lo representan unas $75 \circ 150$, según las épocas. Pertenecen a este conjunto las de Barcelona, Sevilla, Alicante, Málaga, Valencia, Gijón, Béjar... y un relativamente numeroso grupo en el País Vasco, con Bilbao y San Sebastián, o Eibar a la cabeza. Hay que advertir que, en todas estas ciudades, hay sindicatos obreros implantados y relativamente bien organizados y, en algunas de ellas, suele haber concejales socialistas interesados en que las Juntas funcionen. Todo ello al margen de que todas estas Juntas activas hicieran labor positiva en el seguimiento de las leyes sociales. La efectividad dependía en mayor medida en la voluntad política y social de los alcaldes; pero, al menos, desarro- 
llaban actividad. Incluso dentro de este grupo se incluyen Juntas de vida trabajosa y difícil, como la de Madrid, muy criticada y contestada desde diversos sectores.

Otro grupo lo representan las Juntas que sólo esporádicamente, según qué circunstancias, solían reunirse. Las podriamos denominar como Juntas de vida activa circunstancial.

Caben aqui el resto de capitales de provincia y las demás poblaciones relativamente importantes. Se reunian solamente a la hora de establecer algún pacto o acuerdo solicitado por un grupo social determinado, especialmente los comerciantes de la localidad, y más rara vez si lo solicitaba una sociedad obrera - si la había-. En todas ellas dominaba, sin ningún disfrazamiento ni disimulo, la burguesía local. En muchos casos la representación obrera estaba al servicio de aquélla, proviniendo en tales casos de sociedades amarillas no representativas. En otras ocasiones, si habia un representante obrero defensor de los intereses de su clase, estaba siempre en minoría.

En este tipo de Juntas, cuando el asunto que las impulsaba a reunirse era solucionado, lo normal era que la Junta no volviera a reunirse hasta que otro tema de interés incitara la necesidad de una reunión.

Finalmente, un último grupo de Juntas, son las que, habiéndose constitùido formalmente, no ejercieron actividad digna de mención $o$, en todo caso, sólo para elegir presidente de la Junta municipal del Censo. Una vez realizada ésta, que era en realidad un simple parapeto que ocultaba legalmente la designación del alcalde, no volvía la Junta a dar señales de vida.

En este último grupo pueden incluirse la gran mayoría de Juntas de las que se crearon en todo el tiempo, sobre todo en el período comprendido entre 1907 y 1912. Pertenecen la mayoría al medio rural castellano, - gallego y andaluz, especialmente.

Frente a esta división realizada según su activismo, podian hacerse otras atendiendo a aspectos diferentes. Como a la presencia en ellas de distintas fuerzas sociales, tipos de sindicatos, ${ }^{19}$ organizaciones empresariales (comerciales, industriales o agrarias).

\footnotetext{
${ }^{19}$ Dada la gran cantidad de Juntas creadas, se integraron en elias la mayoría de sindicatos existentes en España. La Unión General de Trabajadores en primer lugar, y mucho más atrás, algunos Círculos Católicos, sindicatos profesionales, etc. También sindicatos de empresa, amarillos; recreativos, mixtos... Aunque en las ciudades importantes lo normal era que
} 
El resto de la diversidad entre las Juntas lo marca la propia evolución de éstas. El comportamiento fue variable a lo largo del tiempo en muchas de las Juntas. El motivo no es otro que la diversa actuación que realizan en ellas las fuerzas sociales y políticas que actúan en su interior, y ello en función de las circunstancias locales y generales que se dan en cada momento. Tal diferenciación es observable sobre todo en las Juntas locales del País Vasco. En ellas se muestran comportamientos diferentes según la participación o no del sindicalismo socialista; el mismo sindicato decide su no participación en algunas de las Juntas locales. Un caso especial es la Junta local de Bilbao, probablemente la más indicada para realizar en ella un éstudio pormenorizado y exhaustivo, caso de que permanezcan sus actas y conservados sus informes de inspección. La permanencia temprana y larga de concejales socialistas, y de un tipo generalizado de empresario más moderno y dinámico, junto a la existencia de un sindicalismo, socialista en este caso, organizado y potente, explica el hecho. Mención especial merece la labor inspectora que realizaron las diferentes comisiones de inspección de la Junta a lo largo del tiempo.

\section{LAS JUNTAS DE REFORMAS SOCIALES ANTE LA LEGISLACION LABORAL}

Una de las facultades más importantes que las leyes concedieron a las Juntas fue la de inspeccionar los centros de trabajo. Actividad ésta que se convirtió en una de las más controvertidas y difíciles por culpa de la competencia mutua que se hicieron los inspectores de trabajo y las Juntas que llegaron a ejercer esta labor. En efecto, la facultad inspectora de las Juntas era confusa y chocó numerosas veces con la de los inspectores. Junto a esta atribución existía la que la complementaba: la atribución de imponer sanciones.

Ambos aspectos fueron motivo de crítica constante, sobre todo proveniente de los inspectores de trabajo a través de las conocidas Memorias anuales que estos profesionales confeccionaban, y publicaba el Instituto. La mayoría de estas críticas se referian a la lenidad en materia de imposición de sanciones, lo que era verdad; pero hay que tener en cuenta que

\footnotetext{
la UGT copase las vocalías obreras de las Juntas. La CNT se mantuvo al margen de las Juntas durante todo el tiempo. "Incluso el congreso de 1919 - de la CNT - reprochó duramente a la organización de Barcelona el haber asistido al despacho del alcalde para formar parte de una comisión mixta de patronos y obreros bajo presidencia o arbitraje de la primera autoridad municipal". En J. PeIRATS, Los anarquistas en la crisis política española. Ed. Júcar, 1977, pág. 179.
} 
esta política blanda era ejercida en igual medida por los propios inspectores, muy influidos por la política "persuasiva" y educativa emanada des de el propio I.R.S. Este recomendaba una línea de actuación similar a "...la ejercida por un tornillo que penetra de manera lenta y continua en el trozo de madera que ha de sujetar" ${ }^{20}$. Y reconocía que "...sólo un trabajo lento y perseverante podrá hacer cambiar poco a poco el actual estado de cosas" 21. Por ello, los propios inspectores reconocian: "(Que) no era posible proceder coercitivamente contra los infractores, sino en aquellos casos de más grave y escandalosa infracción" 22 .

Efectivamente, esta "blandura" en la imposición de sanciones por parte de los inspectores puede demostrarse a través de las diferentes Memorias confeccionadas por ellos mismos. Utilizando la de 1917 (si usamos la de otro año nos daría igual o parecido resultado), vemos que de 69.303 infracciones comprobadas en la visita de 2.408 centros de trabajo, solamente se cursaron 83 providencias, de las cuales 39 eran de apercibimiento, 24 de infracción y sólo 18 de multas. De aquellas 69.303 infracciones las hay bastantes graves, como el trabajo nocturno de menores (571 casos) o trabajar más de ocho horas los menores de 14 años (580 casos) ${ }^{23}$.

Por lo tanto, no nos parece achacable solamente a las Juntas la responsabilidad de que las leyes sociales fueran incumplidas. La no muy rrectiva acción de los inspectores es similar a la ejercida por las Juntas ${ }^{24}$.

A ello hay que añadir la situación de la mayoria de los centros de trabajo en España. 'En muchos de ellos su producción se orientaba en el empleo de mano de obra femenina o infantil, con lo que, de haberse cumplido la legislación tutelar hacia ese sector de la población obrera, tales centros hubieran tenido que cerrar sus puertas de inmediato. Su situación técnica y organizativa era claramente preindustrial en lo que se refiere, sobre todo, a la mano de obra indicada. Ejemplo notorio de lo dicho lo representan, entre otros muchos casos, los telares manuales, ubicados preferentemente en las regiones levantina (Alcoy) y catalana. Tal situación justifica en parte, la poca presión sancionadora.

\footnotetext{
${ }^{20}$ BIRS. N. ${ }^{\circ} 52$, octubre, 1908.

${ }^{21}$ BIRS. N. ${ }^{\circ} 57$, marzo, 1909.

${ }^{22}$ BIRS. N. ${ }^{\circ} 68$, febrero, 1910.

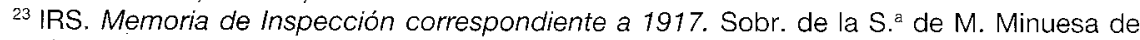
los Ríos. Págs. 303-325.

${ }^{24}$ La insuficiente presión sancionadora de los inspectores es puesta igualmente de manifiesto en la obra de: M.C. PALOMEQUE, Derecho del trabajo e ideología... Op. cit. Pág. 68.
} 
Si a lo anterior unimos el foco de intereses caciquiles de los Ayuntamientos españoles de la época, y dada la indiscutible vinculación económica, social y política de sus alcaldes con los sectores patronales a los que ellos mismos pertenecían en la mayoría de los casos, deduciremos con facilidad la decantación de las primeras autoridades municipales a la hora imponer las medidas coercitivas para que la legislación social protectora fuera respetada. Recordemos una vez más que era su presidente, más que la Junta en sí, quien ostentaba la decisión resolutoria y ejecutiva de estos organismos. Se unían, pues, a los elementos humanos y de interés, los de carácter técnico y económico de las empresas para que fueran alteradas las condiciones tradicionales en la relación capital-trabajo que se daban en España.

Pese a toda esta evidencia, cabe preguntarse ahora el porqué los representantes socialistas reivindicaran el papel inspector de las Juntas pese a reconocerse su ineficacia. Pablo Iglesias, quizás en una de sus primeras intervenciones parlamentarias, al presentar una enmienda al artículo $3 .^{\circ}$ del Proyecto de ley que prohibia el trabajo nocturno de la mujer, que la imposición de las multas la realizarán las Autoridades municipales "cuando lo determinen las Juntas locales y provinciales, y su producción ingresará en las Cajas de las Juntas para mejorar la educación del obrero" ${ }^{25}$.

Insistían los socialistas en dotar a las Juntas de poderes en la inspección y en la acción sancionadora. No es posible a estas alturas tildar de ingenuos a los dirigentes socialistas, pero, -contestando a la pregunta que nos hacíamos más arriba- o pensaban reforzar con su presencia la eficacia de las Juntas en este terreno, o se contentaban con esa eficacia si, en algunas de ellas, bien por la neutralidad de sus presidentes o por la acción de los vocales obreros, iban a llevar a cabo la acción social para la que estaban creadas. Si bien ambos casos se dieron, no resultó positiva en líneas generales la actuación de las Juntas en la inspección y sanción de las ilegalidades que en materia laboral fueron cometidas.

Hay que añadir a la dificultad en la imposición de sanciones por la oposición de los alcaldes, la resistencia impuesta por los patronos de cada fábrica o taller en consentir que sus centros de trabajo fueran inspeccionados, sobre todo si esas visitas eran cursadas por los vocales obreros de las Juntas; oposición que muchas veces fue consentida o amparada por las propias Autoridades gubernativas, gobernadores y alcaldes especialmente.

${ }^{25}$ BIRS. N. ${ }^{\circ} 78$, diciembre, 1910. Del Diario de Sesiones, n. ${ }^{\circ}$ 72, Apéndice 1." (Congreso). 
La Ley protectora de Mujeres y Niños, precisamente la que más facultaba a las Juntas, tampoco puede decirse que fuera respetada en general ral. La indefensión de este sector laboral era completa y la profusión de denuncias llegadas al Instituto sobre su incumplimiento, prueba el abuso e ilegalidad en que se encontraban estos productores.

Hemos mencionado de pasada los métodos de trabajo a los que sededicaban este grupo laboral, cuya producción se orientaba casi exclusivamente al subempleo de estas fuerzas. Junto a ello es de destacar la opinión de muchos padres que obligaban a sus hijos pequeños al trabajo como única forma de incrementar, aunque fuera levemente, los ingresos familiares ${ }^{26}$, y también por la costumbre inveterada, casi como una necesidad, de enseñar a los hijos el oficio que habria de alimentarles el resto de su vida. Incluso, más de una vez, nos encontramos a los propios padres, quizás presionados por los patronos, solicitar al Instituto que fuera exceptuada la ley que impedía el trabajo a los menores de 10 años ${ }^{27}$.

En tal situación, poco podía esperarse de que estas leyes fueran acatadas. El incumplimiento fue general. Solamente al irse modernizando algunas fábricas, sobre todo a partir de 1917, (la sustitución de telares mecánicos por los manuales o la decadencia progresiva de las industrias del esparto, por ejemplo) fue remitiendo el incumplimiento generalizado en esta materia legal. En pequeños talleres y en las zonas rurales la no inclusión de menores en trabajos de diferente tipo es de tiempos casi presentes. Y las Juntas, por todos estos motivos, incluso por la propia opinión general y la de los propios obreros para con sus hijos, poco o nada pudieron hacer.

La inspección se orientó la mayoría de las veces solamente a salvaguardar a los menores y a las mujeres desde una perspectiva moralista. La vigilancia en la exhibición de menores en espectáculos fue más eficaz que la encaminada a impedir su explotación despiadada en los centros industriales. Y ello tanto por las Juntas como por los inspectores del trabajo.

\footnotetext{
26 Sobre la situación del proletariado español de la época, puede consultarse la obra, entre otras, de : F. Romeu Alfaro, "Las clases trabajadoras en España, (1898-1930" Ed. Taurus, 1970.

${ }^{27}$ Esto sucede en las fábricas de hilados de Bocairente (Valencia): tras realizar un inspector la visita a ese centro de trabajo - cuyo propietario era además el alcalde de la ciudad y por lo tanto presidente de la Junta local de Reformas Sociales - el informe que envia al Instituto marca lo terrible de la situación, por ejemplo que trabajan niños de 6 y 7 años, que los horarios infantiles alcanzan las 14,15 y hasta 16 horas diarias, que la enseñanza escolar y religiosa es nula, etc. En BIRS. N. 55 , enero, 1910.
} 
Si nos referimos ahora al cumplimiento de la Ley del descanso dominical digamos que se trata de una de las leyes que con más seguimiento realizaron las Juntas. Desde un principio quedó claro que eran ellas las más indicadas para vigilar su aplicación. Las multas que se impusieron fueron en este caso relativamente numerosas; desde luego, ellas fueron las que engrosaron las Cajas de las Juntas. Bien es cierto que muchas veces se utilizó esta presión sancionadora por los mismos patronos contra otros de la misma localidad; a veces por enfrentamiento político, y otras por simple rivalidad comercial. Con todo, esta ley fue incumplida de manera casi general e hicieron caso omiso de ella tanto patronos, y Autoridades como los obreros mismos. Y cuando se cumplía eran más por factores de indole moral y religiosa que estrictamente laborales. Solamente el paso del tiempo hizo que esta ley fuera más o menos cumplida.

La ley contemplaba amplias posibilidades de excepción, facultad ésta que se concede a las Juntas. Por tal motivo, en numerosas ocasiones ello acarreó protestas de los sectores profesionales afectados, de empleados de comercio especialmente. Generalmente las Juntas tendían a la concesión de excepcionalidad con facilidad.

Hubo una famosa circular clandestina, y anónima, naturalmente, que recorría media España informando de las manera en que se podía burlar la Ley del descanso dominical. Dicha circular fue denunciada por Largo Cabiallero en el I.R.S. y ante el Tribunal Supremo, ya que según el dirigente socialista la circulación de ese anónimo clandestino era favorecida por ciertos funcionarios y oficinas de la Administración, acusación que fue negada por las Autoridades ${ }^{28}$.

Además de ello, dos eran las formas para que, desde dentro de la legalidad, no se cumpliera la ley. Por un lado, el establecer pactos entre los patronos y sus empleados que ajustasen los horarios semanales en forma de turnos y recuperar las horas perdidas en el domingo a lo largo de la semana. Muchos de estos pactos fueron declarados ilegales, y el Instituto tuvo que anularlos cuando protestaba alguna sociedad obrera o los propios delegados socialistas en el Instituto, y ello después que la Junta local correspondiente los hubiera autorizado en un principio. Uno deestos pactos, que fue muy utilizado, consistía en dividir a los empleados de un sector, industria o tienda en internos y externos, comprendiendo a los primeros a menores, encargados, familiares del patrono y obreros adictos a éste, firmando con ellos el pacto que habría de obligar a la totalidad de los empleados. Tal acuerdo, aprobado por la Junta local madrileña y

\footnotetext{
${ }^{28}$ BIRS. N. ${ }^{\circ} 49$, julio, 1908.
} 
corroborado por el Ministerio de Gobernación, finalmente fue denunciado y declarado ilegal ante las denuncias de las sociedades obreras y de los Vocales ugetistas del Instituto ante este organismo ${ }^{29}$.

La otra forma de rodear la ley para no cumplirla era solicitar la instalación de mercados dominicales en núcleos urbanos y barrios. En tal caso, los comercios allí instalados quedaban exceptuados de cerrar los domingos. Con ello, pocos lugares de España quedaron libres de realizar la solicitud y las Juntas en todos los casos fueron favorables a la instalación, tanto por la vinculación comercial de sus integrantes patronales como por el interés de la máxima Autoridad local en incrementar las arcas municipales a través de impuestos y recargos sobre los que instalaban puestos de venta o abrían sus tiendas los domingos.

Otra de las cuestiones polémicas, era la facultad de las Juntas de establecer excepciones en comercios concretos, especialmente en bares y tabernas, lo que fue constante foco de problemas y abusos en numerosos lugares.

Con todo, las Juntas utilizaron con cierta profusión la acción sancionadora (desde luego en mucha mayor medida que en el resto de las leyes sociales), motivado sir, duda alguna por su mayor dedicación en la labor de inspección, puesto que fueron ellas y no los inspectores quienes cubrieron ese trabajo. Tal vigilancia y presión sancionadora fue favorecida por las numerosas y organizadas sociedades obreras, aunque ello era más normal que ocurriera en las grandes ciudades y en tiempos ya avanzados del período que nos ocupa, sobre todo a partir de 1914; también muchos gremios patronales y de comerciantes realizaron labores de inspección para salvaguardar intereses propios ante la competencia desleal que suponía que otros industriales abrieran sus comercios los domingos.

Las leyes reguladoras de la jornada de trabajo, promulgadas entre 1918 y 1919, salieron a la luz con una decidida intencionalidad política de carácter defensivo por parte del Gobierno. Son momentos de crisis política en que el sistema de la Restauración parece venirse abajo por descomposición de sus estructuras ${ }^{30}$. $Y$ en medio de ello una fuerte conflictividad

${ }^{29}$ BIRS. N. ${ }^{\circ} 71$, mayo, 1910.

${ }^{30}$ Sobre la crisis de estos años existe numerosa bibliografia, entre otra, puede verse:

M. TUNON DE LARA, "Rasgos de la crisis estructural a partir de 1917", en La crists del Estado español (1898-1936). Coloquio de Pau Edicusa, 1978.

J.A. Lacomba, La crisis española de 1917. E. Ciencia Nueva, 1970.

J.A. Sagardor Y Bengoechea, El poder sindical en España. Ed. Planeta, 1982. 
social avivada por la carestía de subsistencias y el incremento espectacular del asociacionismo sindical socialista y anarquista.

Todo parece indicar que tales leyes, sobre todo la de jornada máxima de ocho horas, salen en esta ocasión con el propósito firme por parte del Gobierno de que sean cumplidas y acatadas. Por ello, y en líneas generales, fueron leyes sorprendentemente respetadas con cierta rapidez. Hasta el punto de que en la Memoria de Resultados en la aplicación de la jornada de ocho horas, realizada por los inspectores del trabajo y el personal técnico del I.R.S., informan que la implantación de la mencionada norma legal fue casi general a partir del 15 de enero de 1920, diez meses después de su promulgación. Salvo en las localidades - sigue diciendo la citada Memoria- donde se carece de inspector o, por no funcionar la Junta local, se cumple la ley muy deficientemente ${ }^{31}$. Se reconoce, pues, elpapel importante de las Juntas para que la ley se cumpliese.

Refiriéndonos a la mayoría de los empleados españoles, es obligado recordar la importancia numérica, que era mayoritaria, del mundo laboral agrario y el de las poblaciones pequeñas y apartadas. En estos casos el hablar de acatamiento generalizado de la ley de las ocho horas es pura entelequia. Junto a ello, están las amplias excepciones que la ley contemplaba. Los sindicatos obreros criticaron siempre esta excesiva amplitud de las excepciones al cumplimiento legal que se dieron, pero, engeneral, refiriéndonos al mundo industrial y urbano, opinaron muy favorablemente de la aplicación de dichas leyes; aunque siempre lo valoraron como un triunfo propio ${ }^{32}$.

En las grandes ciudades o con alta y media concentración industrial, era normal la existencia de Federaciones sindicales por ramas profesionales y de Asociaciones patronales; en tales casos, la Junta local solía establecer, a requerimiento de las partes en conflicto, pactos y acuerdos relacionados con los horarios de trabajo aprobados por las distintas fuerzas sociales representativas. Estos acuerdos, para limitar la conflictividad diaria o permanente, era normal se hiciesen de duración anual. Y normalmente era la Junta, si era verdaderamente representativa, la encargada de vigilar su cumplimiento por medio de comisiones mixtas de vocales patronales y obreros.

S. Roldan, y J.L. Garcia Delgado, La formación de la sociedad capitalista en España, 19141920. Confederación Española de Cajas de Ahorro, 1973.

${ }^{31}$ BIRS. N. ${ }^{\circ} 196$, octubre, 1920.

${ }^{32}$ El Socialista. Véase los números de abril y mayo de 1919. 
No siempre fue así; conocemos casos de abusos que realizaron algunas Juntas locales, como el de autorizar por ellas mismas el aumento indiscriminado de horas de trabajo semanales; las negativa a reunirse determinadas Juntas cuando eran denunciados hechos parecidos; la no tramitación de multas por infracción de la ley de jornada máxima de ocho horas; no tener comisiones inspectoras que vigilasen su cumplimiento, etc. Aunque casi siempre en tales casos afectan a núcleos rurales o bien a Juntas no representativas de la clase obrera organizada de la ciudad en cuestión. Cuando no se daba este caso y se producía algún abuso, rápidamente la sociedad obrera, bien por ella misma o a través de los vocales socialistas del I.R.S., originaba la protesta que desembocaba en huelga o la llamada al orden por parte del gobernador civil o el propio Ministerio de Gobernación sobre el alcalde infractor.

Se produce una particularidad que merece ser reseñada: las actuaciones más escandalosas en las ciudades o pueblos con cierta implantación industrial protagonizadas por las Juntas, bien sea por alargamiento ilegal de la jornada o por no imponerse o hacer efectivas las sanciones, se dan en Cataluña; precisamente por la mayor implantación del sindicalismo anarquista y situarse éste, como norma, fuera de las Juntas de reformas Sociales, por lo que estos organismos, o muchos de los vocales obreros que las integraban, carecian de toda representatividad y respaldo de la clase organizada del iugar. Esto lo podemos ver en Juntas locales como Gironella, Ripoll, San Juan de las Abadesas, Tarragona, Valls, etc.

En lo que se refiere a la actuación de las Juntas en la mediación y arbitraje, su labor en líneas generales fue de escaso relieve. En un trabajo de seguimiento sobre los conflictos ocurridos y reflejados en los Boletines del Instituto entre 1907 y 1920, la intervención de las Juntas no pasó del cinco por ciento. Siendo la mayoría de ellos tratados mediante los sindicatos, asociaciones patronales, comisiones mixtas de obreros y patronos; les siguen la intervención de las Autoridades y los que no tuvieron intervención de ninguna clase o desconocida.

Hay que aclarar que la intervención arbitral de la Junta no era obligada ni taxativa, sino solamente por conveniencia y decisión de las partes. Teniendo en cuenta que ninguna de ellas podía tener mayoría dentro de la Junta, suponiendo que fueran ambas representativas, resultaba arriesgado exponerse a un laudo o arbitraje que dependía en última instancia delos vocales no representativos y del presidente de la Junta. Arriesgado era, sobre todo, para la parte obrera. El clima social, además, no estaba casi siempre en la disposición de buscar ningún acuerdo previo. Todos los conflictos eran enconados y con el objetivo de dominar al contrario social. 
En otras ocasiones, cuando las Juntas fueron requeridas, era por estar el conflicto estancado y su finalización con éxito era más que difícil. Eso ocurre en la larga huelga de metalúrgicos de Zaragoza, en lade peluqueros y barberos de Valencia (1922), la de impresores de Madrid (1909), o en la de Utrera (1915), que revistió además caracteres tumultuosos. En todas ellas, dadas sus características, la intervención de la Junta local no sirvió para remediar el conflicto. Por el contrario, sí lo solucionó en la larga y enconada huelga de la construcción en Toledo, de 1922, o en la huelga de obreros del campo en Vilallonga, (Tarragona) en 1912.

Junto a la obligación de las Juntas locales (que es a este tipo de Junta a la que nos estamos refiriendo, puesto que las provinciales tuvieron mucha menor trascendencia) de remitir al Instituto la información estadística, (tampoco se distinguieron por su diligencia en este caso), desarrollaron las Juntas algunas iniciativas de tipo voluntario, casi siempre alentadas por individualidades preocupadas ante el problema social. LaJunta local de Valencia organizó un importante Congreso Obrero los días 26 al 30 de octubre de 1909. Participaron en él distintas personalidades de procedencia diversa. Entre sus ponentes figuraron Maluquer, Canalejas, Alvarez Buylla, quien presentó una ponencia sobre organización de bolsas de trabajo organizadas por las Juntas. En Madrid, la Junta local publicó una Estadística del Trabajo, a modo de anuario referido al mundo laboral de la capital.

También adoptaron proposiciones que, elevadas al Instituto se convirtieron en leyes, como la iniciativa de la Junta de San Sebastián y de su inspector provincial por la que se incluyó desde entonces a los jockeys menores de edad sujetos al art. $6 .^{\circ}$ de la ley protectora de mujeres y niños.

Otra de las más activas en este terreno fue la de Barcelona. Por iniciativa de varias sociedades obreras gestiona y consigue, a través del I.R.S., la exención del uso del timbre del Estado en documentos relacionados con la actividad laboral: denuncias, actas de infracción, etc. La Junta de Málaga elevó una Memoria a las Cortes, por mediación del Instituto, referida a la ley de Contratos de Trabajo. La de Bilbao propuso en 1911 la reducción de la jornada máxima en el trabajo de mujeres y niños en las horas nocturnas. Petición que quedaría expresada con la promulgación de la R.O. de 11-VII-1912, prohibiendo el trabajo nocturno de mujeres en fábricas y talleres. Cabe señalar, finalmente, la meritoria labor de la Junta local valenciana (junto a un grupo de médicos è ingenieros interesados por la reforma social) de impedir el peligroso purpurinado a mano de los envoltorios de las naranjas, persiguiendo el trabajo de menores en estas 
labores, el empleo de mascarillas, la ventilación de los locales donde se realizaba y el fomento del empleo de máquinas para este trabajo ${ }^{33}$.

Como conclusión, digamos que, tras reconocer que prácticamente todos los componentes sociales, sindicatos, patronos, Gobierno..., estaban de acuerdo en la existencia de las Juntas de Reformas Sociales, no llegaron a funcionar en la debida forma para la que estaban creadas; idea que, por otra parte, es coincidente con lo ya dicho por la historiografía cuando ha tratado este asunto. Ciertamente, las Juntas no cumplieron el papel que los reformadores sociales les habian asignado, sobre todo si nos referimos a la generalidad de las que fueron creadas, cerca de cinco mil en algún momento. Pero decir esto solamente es dar una valoración excesivamente simplista que no tiene nada que ver con la complejidad y riqueza de detalles que ofrecen estos organismos, tratados objetivamente $e$ inmersos en una realidad igualmente compleja.

Si las Juntas de Reformas Sociales no funcionaron debidamente, salvo excepciones, ese relativo o total fracaso es semejante al que representa la implantación de la reforma social en España, con una sociedad basada en instituciones caducas y nada adecuadas ni receptivas a todo cambio de naturaleza social. De haber funcionado las Juntas hubiera supuesto el hecho un fenómeno verdaderamente inexplicable. Incluso se facilitó desde el poder el deterioro de su función social al dotarlas de facultades con respecto a la Ley Electoral de 1907, como hemos mencionado.

Insistimos que lo que más contribuyó a que las Juntas no realizaran el cometido que el legislador les concedió fue el papel preponderante que en ellas tenía su presidente, alcalde, a su vez, del lugar donde radicaba aquélla. Es de sobra conocida la vinculación económica, social y política a la hora de vigilar el cumplimiento de la legislación laboral y sancionar a los infractores. Sabiendo esto es fácil imaginar su conducta mayoritaria ante la confrontación social y como iba a ser su actuación vigilante y sancionadora.

Ante esta evidencia, cabe preguntarse cómo no fue alterada la composición de las Juntas para que las decisiones tomadas por estos organismos tuvieran mayor poder resolutorio y más fuerza ejecutiva. Evitando, en fin, que todo ese poder y facultades que poseyeron se personalizara en su presidente-alcalde.

${ }^{33}$ BIRS. N. ${ }^{\circ}$ 59, mayo, 1909. 
Para contestar a esta pregunta, que nos daría la clave del fracaso generalizado de las Juntas de Reformas Sociales, hay que referirse a las instituciones y al sistema de poder político vigente en ese tiempo. En efecto, el poder de los alcaldes en los municipios era omnímodo y profundamente engarzado en la cadena caciquil que, como sistema, funcionaba durante la Restauración. Sin embargo el Gobierno no quiso, o no pudo, alterar el doble poder que ostentaron los alcaldes, como delegados del Gobierno, y como máximos representantes del órgano ejecutivo del poder local, los Ayuntamientos. Recordemos que de 1882 a 1923 hubo más de veinte proyectos ministeriales de reforma del gobierno local. Sólo mediante manu militari se logró modificar la situación en la vida municipal.

Una cosa era promulgar la legislación e intentar que se cumpliese en lo posible para frenar la presión obrera, y otra bien distinta modificar en alto grado el status social y de poder establecido en la vida local, que la implantación de las leyes sociales, cumplidas a rajatabla, hubiera supuesto. Junto a estos problemas de naturaleza política, económica y social, estaban, como hemos dicho, los de carácter técnico, dada la situación y orientación productiva en que se encontraban la mayoría de las empresas españolas.

En definitiva, y como conclusión última, digamos que las Juntas de Reformas Sociales cumplieron su labor en los lugares que había organización obrera partícipe en el reformismo social, socialista en este caso; y también en aquellos sitios donde se producía una actitud neutral o contemporizadora por parte de los alcaldes, bien sea motivada por aquella presencia obrera, en algunos casos en los propios Ayuntamientos como concejales, o bien por la actitud personal de algunas de estas máximas autoridades locales. Claro que estos lugares fueron minoritarios, pero allí donde se dieron, las Juntas cumplieron su papel sobradamente, y fueron unos organismos protagonistas en el sentido de que las leyes laborales se hicieran efectivas; aunque, claro está, con los problemas y las resistencias previsibles en una sociedad atrasada tanto en métodos de produción como en formas de comportamiento ante una realidad social nueva.

En el resto de los lugares, con relaciones económicas y sociales claramente preindustriales, las Juntas fueron absorbidas, la mayoría de las veces, en el juego político localista y caciquil controlado por la clase dominante, clase que era, además, una de las partes intervinientes en el conflicto social y presente en las Juntas desde un doble lado: representacionalmente por los vocales patronales y desde la presidencia de la Junta por el alcalde. La función de las Juntas, en tales casos, fue nula o contraria a los fines encomendados. 